\title{
Educación y formas de dominación en Max Weber
}

\author{
Gonzalo Cataño*
}

A diferencia de sus contemporáneos el francés Émile Durkheim y el norteamericano Thorstein Veblen, Max Weber nunca escribió un libro sobre educación. Sus numerosas reflexiones sobre la enseñanza se encuentran dispersas a lo largo de toda su obra en lugares subordinados que tienden a disminuir su papel y su significado en la sociedad. Unas veces se la ve encadenada a la política - a las formas de dominación-y otras a la economía, el derecho, la religión y la ciencia. En sus libros de gran tamaño, en Economía y sociedad, en las monografías sobre las religiones universales, en los estudios históricos, la educación aparece como un elemento más del tejido social con ímpetus particulares según las demandas sociales y los intereses de los grupos en cuestión. Allí se la ve unida a la estratificación social, a los factores de prestigio, a la multiplicación de la especialización ocupacional, al despertar de condiciones únicas en el espíritu de los jóvenes, o a funciones opuestas como el aprendizaje de habilidades rutinarias, la transmisión de saberes generales o la ampliación de oportunidades mediante la masificación de la labor escolar.

En esta visión panorámica, Weber resalta los distintos escenarios institucionales que promueven los procesos educativos: escuelas, colegios y universidades para los tiempos más recientes; cuarteles, talleres, monasterios e internados para el pasado y los tiempos más remotos. Unas veces las instituciones aparecen en manos privadas o de la Iglesia y del Estado, y otras a cargo de guildas, grupos guerreros o asociaciones profesionales de diverso tipo (y aún más, de una compleja combinación de uno y otro). Todas sus acciones llevan la misma impronta: transmiten conocimientos y creencias mediante una relación disciplinada entre el que enseña y el que aprende. El propósito de Weber era mostrar las múltiples formas mediante las cuales se reproduce un tipo social deseado - el caballero, el especialista, el sacerdote, el funcionario, el guerrero, etc. - en estrecha relación con la organización del poder en la sociedad. Para ello bosquejó una tipología sociológica de los objetivos y medios pedagógicos derivada de su teoría de las formas de dominación. Con esta estrategia analítica quería explicar tanto las sociedades actuales como las del pasado; el mundo Occidental como el Oriental; Grecia y Roma; la India, la China y el Japón; Israel, el antiguo Egipto y las sociedades primitivas tan próximas a los antropólogos.

Como se sabe, Weber distinguió tres tipos de dominación basados en diferentes fuentes de legitimidad: la legal, la tradicional y la carismática. La dominación legal, típica de las sociedades modernas, se manifiesta en el ejercicio de la autoridad mediante el acatamiento de leyes previamente estatuidas y aceptadas por los miembros de la sociedad. Se obedece a un individuo, al "burócrata", no en virtud de un derecho propio que le confiere su nacimiento o un rasgo particular y único de su carácter, sino en cuanto encarna ciertas reglas a las cuales él mismo está sujeto. Allí el que ordena, obedece; sus exigencias son la mera prolongación del eco de las normas. La dominación tradicional, propia más no exclusiva de la era patriarcal, del mundo medieval y de los sultanes

\footnotetext{
* Sociólogo. Profesor titular de la Universidad Pedagógica Nacional. Autor de La Sociología en Colombia (tercera edición, 1997). Educación y estructura social (1989), La artesanía intelectual (1995). Historia, sociología y política (1999) y Crítica sociológica y otros ensayos (2000).
} 
otomanos, reside en la creencia de la santidad de los mandatos derivados del poder señorial. El "señor" es quien ordena y los que obedecen llevan el aliento del "súbdito". Se acata a la persona en virtud de una dignidad santificada por una tradición sancionada generación tras generación; "válida desde siempre". Es el imperio de los usos y costumbres originados en tiempos remotos que se extravían en el mito. Allí los funcionarios dependen directamente del señor y administran su gracia en calidad de parientes, favoritos y vasallos amparados por la fidelidad.

La dominación carismática, la temida adversaria de las autoridades legal y tradicional, funda su influencia en las dotes sobrenaturales de las personas o de las instituciones: en el heroísmo, en las facultades mágicas, en el don de la revelación, en la capacidad oratoria, en el talento intelectual. Sus mejores ejemplos son el profeta y el santo, el reformador y el conquistador, el revolucionario y el demagogo. Es la manifestación de lo excepcional, del genio y la grandeza emparentados con el hechizo. Se obedece al jefe, que toma la forma del "caudillo", no por su dignidad tradicional o por el ascendiente que descansa en la costumbre o en un estatuto jurídico, sino por su carisma, por sus cualidades singulares y únicas. La dominación carismática es por naturaleza una autoridad inestable y precaria a pesar del ímpetu inicial que la acompaña. El "paladín" pierde influencia cuando su dios lo "abandona" — cuando deja de hacer milagros o cuando sus revelaciones no se cumplen-. O aún más, cuando decae su heroísmo y cuando se muestra incapaz de "electrizar» las masas o de iluminar a los seguidores más cercanos, los "apóstoles". Es la manifestación de la transformación y el cambio; siempre la asiste una irradiación sediciosa hasta confundirse con la subversión. Su empeño es la lucha sin cuartel contra lo establecido, contra los valores, los hábitos, las leyes y las tradiciones consideradas eternas e imperecederas. Con exhalación divina busca una sumisión a lo que todavía no existe pero que sería digno de alcanzar. En palabras de Weber, "es el poder revolucionario específicamente creador de la historia"155.

Como ocurre con las construcciones teóricas de Weber, la elaboración anterior es una construcción típico-ideal dirigida a orientar la observación de los hechos y de las situaciones concretas. La realidad es siempre más compleja y ofrece una combinación de uno y otro tipo en una gradación no siempre fácil de establecer. Es labor del investigador evaluar el peso de los elementos constitutivos de los casos específicos a fin de evitar presentaciones esquemáticas y poco flexibles de los hechos. Weber unió sus reflexiones educativas a esta tipología y, siguiendo los rasgos más sobresalientes de su construcción típico-ideal, fijó la atención en los mecanismos de reproducción de las formas de autoridad. Su énfasis se dirige a la preparación de la clase política de mayor rango y a la formación de sus inmediatos colaboradores (del cuadro administrativo encargado de la gestión del Estado y demás organismos de gobierno). Si bien en la época de Weber el sistema escolar se estaba extendiendo de manera irresistible a todos los estratos de la sociedad, todavía la educación en sus niveles secundario y superior se hallaba unida a las clases altas y a las ocupaciones directivas. Por aquellos años la universidad era una "escuela de burócratas", según las gráficas palabras del jurista, sociólogo y economista alemán Lorenz von Stein ${ }^{156}$.

Weber encontró que a lo largo de la historia se podían distinguir claramente dos objetivos formativos contrapuestos: uno que buscaba despertar cualidades particulares en los jóvenes y otro que insistía en una formación especializada de los aprendices. En su estado puro el primer tipo correspondía a la estructura carismática de la dominación y el

\footnotetext{
${ }^{155}$ M. Weber, Economía y sociedad (México: Fondo de Cultura Económica. 1964), vol. II, p. 853. El énfasis es de Weber.

${ }^{156}$ Citado por Hans Gerth y C. Wright Mills, Carácter y estructura social (Buenos Aires: Paidós, 1963), p. 244.
} 
segundo a la estructura burocrática racional, típica de las sociedades modernas. Entre estos tipos polares encontraba a su vez una gama de objetivos educativos que intentaban cultivar en el educando el estilo de vida característico de un grupo social más o menos cerrado, que Weber —evocando la estratificación social del mundo medieval— llamaba estamento.

Aunque en sentido estricto los dones carismáticos no son susceptibles de ser transferidos, pues se espera que quienes están destinados a encamar lo particular y único llevan una huella especial desde su nacimiento, la acción educativa se hace indispensable para despertar las facultades que existen de manera latente en el "alma" del novicio. Tanto el santo, el hechicero y el legislador como el artista, el sacerdote y el conductor de la guerra, deben pasar por un entrenamiento dirigido a templar y probar sus dotes. El genio nace pero hay que formarlo; se deben cincelar sus rasgos para asegurar el éxito de su destino. No es extraño entonces que la educación carismática tenga lugar en internados y escuelas especiales que separan al aprendiz de sus lazos familiares y de sus ambientes cotidianos más cercanos, Muchas instituciones "exclusivas", de "élite", cumplen funciones semejantes en nuestros días. Y ello porque la formación carismática tiende a ser esotérica, esto es, reservada y para unos pocos. Su clima más adecuado es la comunidad, retirada de maestros y alumnos sometidos a una disciplina intensa que facilita la instrucción en prácticas corporales, ejercicios espirituales, conductas ascéticas, torturas y mutilaciones que buscan despertar el éxtasis adormecido en el corazón de los pupilos. Su sentido es la corroboración, la prueba y selección de la persona cualificada. El entrenamiento termina con la recepción solemne del candidato en el círculo de los portadores comprobados del carisma. Ahora sus tutores se han convertido en sus colegas y en sus compañeros de misión, y con la experiencia y los años, tendrá a su cargo labores de instrucción con alumnos que es buscan avivar sus adormecidos atributos personales.

La educación que nutre la autoridad tradicional tiene un énfasis diferente. Sus marcos cultivan en el educando un estilo de vida asociado con el ideal cultural de un estrato dominante (un estamento). Los ejemplos favoritos de Weber eran la formación del samurai japonés, del mandarín chino, del junker alemán, del gentleman inglés, de los grupos dirigentes de la Grecia y Roma antiguas y de la amplia gama de notables, los honoratiores, muy corrientes (más no exclusivos) de la Edad Media y de los años que siguieron al Renacimiento. Todos ellos integran los efectivos de la administración de los organismos tradicionales. El objetivo de esta modalidad educativa es la adquisición de las maneras, el porte y los conocimientos característicos del estrato al que se pertenece o al que se quiere acceder. Lejos se está aquí del entrenamiento especializado del experto o de la adquisición de saberes útiles y aplicados. El especialista, el "técnico", es en estos medios fuente de escarnio y de franco desprecio. Los delegados de la dominación tradicional ostentan sin duda destrezas en un campo particular - habilidades militares, teológicas o jurídicas-, pero esto es sólo un elemento más de su formación y se encuentra subordinado al ideal del hombre "integral", de la persona "cultivada". El caballero medieval se educaba en asuntos militares de la misma forma que adquiría destrezas en las artes, la danza y el canto, además de la literatura, el juego, el lenguaje y los modales cortesanos. La instrucción despliega allí una fuerza especial, hasta el punto de que en estructuras de dominación tan diferentes como las feudales, las teocráticas y las patrimoniales, el "cultivo" es percibido por las masas como la fuente última de la diferenciación social. En nuestros días su estela pervive en el bachillerato clásico y en la labor de seminarios y academias que buscan al hombre total, indiviso y "completo". En ella el conocimiento general es definido como fuente de enriquecimiento y ornamento de la personalidad, y sus instituciones se reclaman al modelo ilustrado de la Grecia y Roma clásicas, exaltado siglos 
después por el ideal humanista del Renacimiento que ha pervivido en Occidente hasta nuestros días. Con todo, el mayor peligro de esta educación es la de alimentar la pretensión de honor y respeto particulares del estamento. Para prever el desarrollo de una molesta autonomía que ponga en cuestión los poderes establecidos, la autoridad tradicional se cuida siempre de elegir a los miembros de sus cuadros administrativos «desde arriba», es decir, como favor personal y no como concesión de legitimidad a un grupo independiente con pretensiones de autonomía. Con esto se busca coartar los intentos de afirmación de un poder separado que subvierta la noción de fidelidad unida al otorgamiento del «favor». Se observa piedad y devoción al superior que elige (pues toda elección emana de su voluntad) y no al estamento que certifica la formación.

La educación racional (moderna) barre con los fines más queridos de lo tradicional y carismático. Su meta es la instrucción especializada, funcional y útil. Es la educación de la civilización capitalista por excelencia que a continuación heredaron los proyectos socialistas gestados en sus entrañas. En la sociedad moderna lo que cuenta es el conocimiento científico especializado, la preparación tecnológica, y todo ello a expensas de la cultura humanística. Sus ejemplos más acabados son las escuelas técnicas de la enseñanza media y las ramas especializadas de la universidad. En sus predios se entrena para ocupaciones que exigen habilidades y destrezas específicas; aquí el ocio, la placidez y la desidia mercantil del caballero medieval, constituyen un "pecado" y un desvergonzado derroche. Sus moldes han destruido las amadas nociones heroicas del honor, el juego y sus afinidades con lo artístico. El reino de los conocimientos útiles racionalmente controlados se ha instalado en la cultura y ha dejado de lado las conductas lúdicas que recreaban el universo de los miembros de los estamentos directivos. La persona idónea, no el hombre culto, es el ideal educativo de la era $Y$ burocrática. El título conferido por las instituciones escolares, después de haber superado las pruebas y exámenes respectivos, se erige airoso en el mercado de trabajo, desterrando las pretensiones de "limpieza de sangre" como requisito para alcanzar prebendas, gracias y puestos oficiales. Y para sectores de la población cada vez más amplios, el éxito parece residir en el poder de una "casta" que afirma su dominio en un conocimiento certificado, esto es, en una meritocracia basada en el diploma.

Como ocurre con los tipos de dominación que confieren vida a estos modelos educativos, ninguno de ellos se presenta jamás en estado puro. A las manifestaciones dominantes de uno de ellos se unen elementos de los demás, hasta formar un entramado no siempre claro para el analista social. Cuando un seminarista —un humanista en el sentido más amplio y menos exigente de la palabra - finaliza sus estudios después de aprobar una serie de exámenes previamente establecidos y formalizados, está listo para alcanzar la ordenación sacerdotal. Allí se está al frente de un ejemplo de formación general que ha sido sometida a pruebas racionales para acceder a una posición que transforma un individuo corriente en persona "sagrada", en un ser portador de dotes especiales.

Esta es en pocas palabras y en forma bastante apretada, el tratamiento más orgánico que Weber ofreció sobre educación. Sin duda que también se refirió a otros asuntos, sobre todo en lo que respecta a situaciones contemporáneas. Como es de conocimiento de los lectores de la Revista Colombiana de Educación, Weber se ocupó en diversos momentos de su vida de los problemas universitarios ${ }^{157}$. En un lenguaje acerado, donde el polemista y el analista social iban parejos, en varios trabajos discutió la naturaleza de la

\footnotetext{
${ }^{157}$ Max Weber, «El poder del Estado y la dignidad de la vocación académica», Revista Colombiana de Educación, No. 21, Bogotá, 1990, pp. 7-99.
} 
educación superior y las políticas más adecuadas para su desarrollo. Para Weber la universidad tenía una función adicional a la formación de funcionarios y profesionales. No cabe duda de que transmite experiencias y habilidades, como ya lo había apuntado al caracterizar la educación racional, pero a diferencia de los demás ciclos del sistema educativo, contribuye al desenvolvimiento del saber. A través de la investigación colegiada de profesores y estudiantes, pone en cuestión el conocimiento establecido y abre nuevos caminos para su futuro desenvolvimiento. En sus aulas se ha alojado la ciencia, esa dimensión de la cultura occidental que apenas conocieron las tradiciones intelectuales de Oriente. Sólo en Europa "hubo ciencia en el estadio de desarrollo que hoy consideramos válido", insistió al final de su vida ${ }^{158}$. Surgió a finales del Renacimiento y se afirmó definitivamente en el siglo XVII sobre bases teóricas, matemáticas, empíricas y experimentales racionales, que hicieron de ella el instrumento de conocimiento más seguro para revelar los secretos de la naturaleza y las brumas que ocultan la acción social, el objeto de estudio de la sociología. Y fue a este aspecto panicular de la vida universitaria, que Weber concedió una segunda atención a lo largo de sus escasas y dispersas reflexiones educativas.

El tema era de gran relevancia en su tiempo, como lo sigue siendo en nuestros días. Durante el siglo XIX la ciencia había entrado de lleno a los recintos universitarios, compitiendo exitosamente con las antiguas academias, las sociedades reales o las asociaciones informales de sabios dirigidas a discutir las investigaciones y difundir sus resultados. Ahora se hacía necesario proteger el trabajo de los institutos y de las facultades de la acción de poderosos agentes como la política, la religión o los negocios. En pocas palabras, afirmar la autonomía del saber respecto de intereses extraños que podían limitar el desarrollo de su tarea. Para Weber era claro que una vez que el trabajo científico se había fusionado con la labor docente, el prestigio de las universidades se derivaba de su relación con la ciencia y las contribuciones que fuera capaz de hacer al avance del conocimiento. En estas reflexiones el énfasis no estaba puesto en el aparato educativo como medio de reproducción de los estratos directivos, sino como residencia de la ciencia, como el lugar que habita uno de los grupos sociales más creativos de la sociedad.

\section{Criterio de esta compilación}

En esta entrega de la Revista Colombiana de Educación se ofrecen los textos analíticos de Weber en materia de educación. Salvo el orientador sumario, "Los tipos sociológicos de educación>, los demás escritos han sido traducidos especialmente para esta edición. Ellos pertenecen a Economía y sociedad, el gran esfuerzo sistemático que el famoso sociólogo alemán no logró concluir y que hoy leemos en compilaciones post mortem. Como lo han experimentado todos aquellos que han trasegado por el millar de páginas de esta obra infinita, Economía y sociedad es un texto espeso, hermético ya veces francamente impenetrable. El lector lucha una y otra vez con sus folios y a lo largo de ellos se ve inmerso en una sucesión de observaciones históricas y económicas, etnológicas y jurídicas no siempre fáciles de discernir Pero cuando se superan las obstáculos, la visión se ensancha y los vínculos de la educación con las demás esferas de la sociedad y de la cultura adquieren una dirección mucho más rica y compleja.

La traducción sigue la edición norteamericana de Economía y sociedad, versión que ha recibido los aplausos de los eruditos por la solidez de la interpretación y por el eficaz

\footnotetext{
${ }^{158}$ M. Weber, Sociología de la religión (Madrid: Istmo, 1997), p. 313. El énfasis es de Weber. Digitalizado por RED ACADEMICA
} 
aparato crítico que la acompaña ${ }^{159}$. Sólo resta esperar que este nuevo esfuerzo de la Revista Colombiana de Educación contribuya a enriquecer los estudios educativos y el análisis de las instituciones escolares de América Latina.

\footnotetext{
${ }^{159}$ Max Weber, Economy and society: an outline of interpretative sociology (Berkeley: University of California Press, 1978), 2 vols. Edición a cargo de Guenther Roth y Claus Wittich.
} 